\title{
Can Spirometry, Pulse Oximetry and Dyspnea Scoring Reflect Respiratory Failure in Patients with Chronic Obstructive Pulmonary Disease Exacerbation?
}

\author{
Melek Sedef Güryay ${ }^{a}$ Emel Ceylan ${ }^{d}$ Türkan Günay ${ }^{b}$ Sevilay Karaduman ${ }^{a}$ \\ Fecri Bengi $^{\mathrm{a}}$ İsmet Parlak ${ }^{\mathrm{a}}$ Metin Çiçek ${ }^{\mathrm{a}}$ Arif H. Cımrın ${ }^{\mathrm{c}}$ \\ Departments of a Emergency Medicine, ${ }^{b}$ Public Health and ${ }^{c}$ Chest Diseases, Faculty of Medicine, Dokuz Eylül \\ University, İzmir, and d Department of Chest Diseases, Faculty of Medicine, Adnan Menderes University, Aydın, Turkey
}

\section{Key Words}

Chronic obstructive pulmonary disease $\cdot$ Respiratory

failure $\cdot$ Pulse oximetry $\cdot$ Dyspnea scoring $\cdot$ Spirometry

\begin{abstract}
Objective: To evaluate the extent to which oximetry, spirometry and dyspnea scoring can reflect hypoxemia and hypercapnia among patients admitted to the emergency department (ED) with acute exacerbations of chronic obstructive pulmonary disease. Subjects and Methods: Spirometry, oxygen saturation by pulse oximetry $\left(\mathrm{SpO}_{2}\right)$, arterial blood gas analysis and dyspnea scoring assessments were made in the ED. Correlations of these parameters were evaluated by means of Pearson's test. Pulse oximetry cutoff values to express hypoxemia were demonstrated by receiver operating characteristic (ROC) curves. Results: 76 patients with a mean age of 68.0 years were included in the study. Mean spirometric values, expressed as percentages of predicted values, were forced expiratory volume in $1 \mathrm{~s}\left(\mathrm{FEV}_{1}\right)=$ $23.1 \pm 9 \%$; forced vital capacity (FVC) $=32.8 \pm 11 \%$, and mean $\mathrm{FEV}_{1} / \mathrm{FVC}=72.4 \pm 21.6 \%$. While there was a positive correlation between the $\mathrm{SpO}_{2}, \mathrm{SaO}_{2}$ and $\mathrm{PaO}_{2}$ values $(\mathrm{r}=0.91$ and 0.80 , respectively), a negative correlation $(r=-0.74)$ was observed between $\mathrm{PaCO}_{2}$ and $\mathrm{SpO}_{2}$. In determining hypoxemia, both $\mathrm{SpO}_{2}$ and $\mathrm{FEV}_{1}$ were sensitive (83.9 and 90.3\%,
\end{abstract}

respectively) while dyspnea scoring was the most sensitive (93.5\%). In the evaluation by means of an ROC curve, a saturation of $88.5 \%$ for the pulse oximeter was the best cutoff value to reflect hypoxemia (sensitivity $95.6 \%$, specificity $80.6 \%$ ). Conclusion: $\mathrm{SpO}_{2}$ alone appears to be as highly specific as a combination of other tests in the evaluation of hypoxemia. A cutoff value for $\mathrm{SpO}_{2}$ of $\leq 88.5 \%$ is proposed as a criterion in screening for hypoxemia.

Copyright $\odot 2007$ S. Karger AG, Base

\section{Introduction}

According to a report of the World Health Organization, chronic obstructive pulmonary disease (COPD) was the sixth leading cause of death in the world, and it is estimated that by the year 2020, COPD will be the third leading cause of death and the fifth leading cause of disability worldwide [1, 2]. Moreover, approximately $10 \%$ of all hospitalizations are attributable to COPD [3]. The mortality risk for acute exacerbations of COPD (AECOPD) has been shown to be about 8 and 23\%, respectively, in hospital and 1 year after discharge in a prospective study [4].

Patients with COPD exacerbations are frequently referred to the emergency department (ED), but during the

\section{KARGER}

Fax +4161306 1234

E-Mail karger@karger.ch

www.karger.com
(C) 2007 S. Karger AG, Basel

1011-7571/07/0165-0378\$23.50/0

Accessible online at:

www.karger.com/mpp
Dr. Emel Ceylan

Cumhuriyet mah. 1962 sok. No: 30/4

TR-09020 Aydin (Turkey)

Tel. +90256214 9974, Fax +902562146495

E-Mailemel_ceylan@yahoo.com 
treatment period there, it is not always easy for the clinician to make a decision about discharge of the patient from the ED or whether to keep the patient hospitalized for monitoring. Direct measurement of the pulmonary function with a bedside spirometer and arterial blood gas (ABG) analysis have been suggested as valuable measurements when determining the severity of an AECOPD and in making a decision about the state of the patient [5-7]. Although physical examination is important in the evaluation of the patients in ED, the signs of airway obstruction are not always obvious before a significant deterioration in pulmonary function [8]. To what extent is it justified to make a decision about the severity of the disease on the basis of forced expiratory volume in $1 \mathrm{~s}\left(\mathrm{FEV}_{1}\right)$ during the period of acute attack? Lung function tests may be difficult for sick patients to undergo. Also in Turkish hospitals, a costly method like ABG analysis is not always available.

According to current clinical practice, patients suffering from acute hypoxemia or hypercapnia are hospitalized [9]. However, COPD patients with chronic respiratory insufficiency are usually both hypoxemic and hypercapnic.

The present study was undertaken to identify tests using simpler technical equipments to determine COPD severity and evaluate patients more effectively. The question posed was whether or not spirometry, pulse oximetry and dyspnea scoring would reflect respiratory failure in patients with COPD exacerbations. These measurements were assessed regarding their merit for identifying hypoxemia and hypercapnia in comparison with results from the ABG analysis of samples.

\section{Methods}

The study was carried out during January to September, 2001, in the Department of Emergency Medicine, Faculty of Medicine, Dokuz Eylül University, Izmir, Turkey, after obtaining approval of the local Ethics Committee. Seventy-six patients, mean age 68 \pm 9.3 years (range 48-90), 47 male and 29 female, were included in the study. All were followed up in a Chest Clinic for $9.0 \pm 7.6$ years (range 1-35). Each patient signed an informed consent form and completed a questionnaire giving demographic and health particulars.

Seventy-four of the 76 patients had been using various bronchodilator drugs and 25 of them were administered continuous oxygen therapy due to respiratory failure. In 28 , there were additional diseases accompanying COPD, such as congestive heart failure and coronary artery disease. Fifty-eight patients were smokers and the mean amount of smoking was $29 \pm 13$ packs per year (range 10-60).

Monitoring Respiratory Failure in COPD

Exacerbations
Diagnosis and severity of COPD were established by a respiratory physician on the basis of Global Initiative for Chronic Obstructive Lung Disease criteria [10]. Existence of at least one of the following criteria was considered an acute exacerbation of the COPD patient: worsening of dyspnea, increase in sputum production and/or purulence. Exclusion criteria were being under the age of 40 years, lack of cooperation, early intubation due to respiratory failure, inability to perform spirometry, having asthma, or another acute condition, i.e., pneumonia, pneumothorax, pulmonary emboli or acute congestive heart failure warranted hospital admission.

Pulse rate, blood pressure, temperature values and the respiration rate were measured; chest radiograph was taken through the use of a portable X-ray machine to rule out other acute comorbid conditions. Bradypnea was accepted if the respiration rate was below $12 / \mathrm{min}$ and tachypnea if above $20 / \mathrm{min}[11,12]$. Pulmonary function tests, $\mathrm{ABG}$ analysis, oxygen saturations obtained with pulse oximetry $\left(\mathrm{SpO}_{2}\right)$ and dyspnea scoring were determined. The condition of the patients after treatment (being discharged from the ED or being hospitalized) and monitoring were all reported in the questionnaire.

Pulmonary function tests were assessed with forced expiratory maneuvers through the use of the portable Micro Medical Micro Plus Spirometer which was calibrated and checked weekly with a 6-liter injector with an outer connection of $30 \mathrm{~mm}$ length. The physician demonstrated the procedure to all patients. Prior to beginning any treatment, the patient was asked to perform the maneuver while seated and wearing nose clips. Each patient performed at least two or three acceptable forced expiratory maneuvers. The highest values of measured $\mathrm{FEV}_{1}$, forced vital capacity (FVC) and peak expiratory flow (PEF) were obtained and shown as a percentage of predicted normal values based on age, height and sex according to the European Community for Coal and Steel report [13]. Based on the GOLD criteria [10], COPD was considered very severe if $\mathrm{FEV}_{1}$ was $<30 \%$ of the predicted value; severe if $30 \leq \mathrm{FEV}_{1}<50 \%$; moderate if $50 \leq \mathrm{FEV}_{1}<80 \%$, and mild if the $\mathrm{FEV}_{1} / \mathrm{FVC}$ ratio was $<70$ and $\mathrm{FEV}_{1} \geq 80 \%$ of the predicted value.

A blood gas sample while breathing room air was obtained from the radial artery before the initiation of any therapy. The arterial blood was collected in a heparinized glass syringe, placed on ice and immediately transported to our laboratory for analysis on the model Nova Stat 9. The $\mathrm{pH}, \mathrm{PaO}_{2}, \mathrm{PaCO}_{2}, \mathrm{HCO}_{3}$ and $\mathrm{SaO}_{2}$ values were measured. $\mathrm{PaO}_{2}<60 \mathrm{~mm} \mathrm{Hg}$ in $\mathrm{ABG}$ as hypoxemia, and $\mathrm{PaCO}_{2}>50 \mathrm{~mm} \mathrm{Hg}$ as hypercapnia were considered acceptable as reference values [14].

$\mathrm{SpO}_{2}$ values were obtained by a pulse oximeter (Athena) before treatment while breathing air, and were recorded as a percentage of saturation. Throughout monitoring, patients were followed with pulse oximetry. Those with $\mathrm{SpO}_{2}$ values $<90 \%$ were considered to have a respiratory failure as well as hypoxemia $[10,15]$. For an objective evaluation of dyspnea, a five-stage scoring system suggested by the American Thoracic Society was used. Dyspnea scores 3 and 4 were regarded as serious dyspnea [15].

\section{Statistical Analysis}

SPSS 10.0 statistics program was used to conduct the statistical analysis. The correlations between pulmonary function test parameters, $\mathrm{SpO}_{2}$ values, the results of $\mathrm{ABG}$ analyses and dyspnea scoring were evaluated by means of Pearson's test. Sensitivity, 
specificity, negative and positive predictive values of the use of dyspnea scoring and pulse oximetry were evaluated. Additionally, an index was developed which was defined as: $\mathrm{A}=\mathrm{FEV}_{1}$ $<30 \%+\mathrm{SpO}_{2}<90 \%$; $\mathrm{B}=\mathrm{FEV}_{1}<30 \%+\mathrm{SpO}_{2}<90 \%+$ severe dyspnea scores; $\mathrm{C}=\mathrm{SpO}_{2}<90 \%+$ severe dyspnea scores. The sensitivity, specificity, negative and positive predictive values were calculated using this index. The pulse oximetry cutoff values to express hypoxemia were demonstrated by drawing receiver operating characteristic (ROC) curves.

\section{Results}

At the first evaluation in the ED, a mean pulse rate of $106 \pm 20$ beats/min, a mean systolic blood pressure of 151 $\pm 28 \mathrm{~mm} \mathrm{Hg}$ and a mean diastolic blood pressure of 95 $\pm 19 \mathrm{~mm} \mathrm{Hg}$ were detected. The mean respiration rate was $33 \pm 6$ breaths/min (range 24-48), and the mean dyspnea score was $2.9 \pm 0.9$ (range $0-4$ ); clinically serious dyspnea (levels 3 and 4) was present in 55 patients (72\%). Mean spirometric percentages of predicted values were: $\mathrm{FEV}_{1}=23 \pm 9.3 \%, \mathrm{FVC}=33 \pm 11.5 \%, \mathrm{PEF}=20 \pm$ $10.9 \%$, and mean $\mathrm{FEV}_{1} / \mathrm{FVC}=72.4 \pm 21.6 \%$. In the spirometric evaluation of cases during the postexacerbation period, mean $\mathrm{FEV}_{1}$ of patients was $40.6 \pm 15.2 \%$, mean $\mathrm{FVC}$ was $56.1 \pm 17.4 \%$, and mean $\mathrm{FEV}_{1} / \mathrm{FVC}$ was $55.8 \pm$ $12.5 \%$. When referred to the $\mathrm{ED}, \mathrm{FEV}_{1}$ was $<30 \%$ of the predicted value in $61(80 \%)$ of the patients, and in 2 it was $>50 \%$ of the predicted value. Twenty-eight $(36.8 \%)$ of the patients were hospitalized. Those hospitalized had lower $\mathrm{FEV}_{1}, \mathrm{SpO}_{2}$ and $\mathrm{PaO}_{2}$ values than the nonhospitalized or those discharged from $\mathrm{ED}$. $\mathrm{PaCO}_{2}$ and dyspnea scores were higher in hospitalized patients. While $\mathrm{SpO}_{2}$ of hospitalized patients was $79.6 \%$ on average, that of discharged patients was $91.9 \%$, and while $\mathrm{PaO}_{2}$ of hospitalized patients was $50.1 \mathrm{~mm} \mathrm{Hg}$, that of those discharged was 66.2 $\mathrm{mm} \mathrm{Hg}$.

Mean ABG values were as follows: $\mathrm{pH}=7.40 \pm 0.04$ (range 7.30-7.51); $\mathrm{PaO}_{2}=60 \pm 24$ and $\mathrm{PaCO}_{2}=46 \pm 14$ $\mathrm{mm} \mathrm{Hg} ; \mathrm{SaO}_{2}=87 \pm 10 \%$. Thirty-one patients (41\%) were determined to be hypoxemic and the average $\mathrm{pH}$ was $7.38 \pm 0.05$. In the remaining 45 cases, the $\mathrm{PaO}_{2}$ value was $>60 \mathrm{~mm} \mathrm{Hg}$ and the mean $\mathrm{pH}$ was $7.41 \pm 0.03$. There was a very strong correlation $(\mathrm{r}=0.91, \mathrm{r}=0.80)$ of the $\mathrm{SaO}_{2}$ and $\mathrm{PaO}_{2}$ with $\mathrm{SpO}_{2}$ values $(\mathrm{p}=0.000$ and 0.000 , respectively), whereas there was again a strong but a negative correlation $(\mathrm{r}=-0.74 ; \mathrm{p}=0.000)$ between $\mathrm{PaCO}_{2}$ and $\mathrm{SpO}_{2}$ values. Additionally, reasonable correlations were observed between $\mathrm{FEV}_{1}$ and $\mathrm{PaO}_{2}$ and between dyspnea score and $\mathrm{PaO}_{2}$ (table 1). These values indicate that a deterioration in the $\mathrm{ABG}$ values that accompanies wors-
Table 1. The correlation coefficients between the ABG values and pulse oximetry results

\begin{tabular}{lrrr}
\hline & $\mathrm{PaCO}_{2}$ & $\mathrm{PaO}_{2}$ & $\mathrm{SpO}_{2}$ \\
\hline $\mathrm{FEV}_{1}$ & $-0.44^{*}$ & $0.40^{*}$ & $0.16^{*}$ \\
$\mathrm{FVC}$ & $-0.36^{*}$ & $0.35^{*}$ & $0.35^{*}$ \\
$\mathrm{PEF}$ & $-0.30^{*}$ & 0.13 & $0.23^{*}$ \\
$\mathrm{SpO}_{2}$ & $-0.74^{*}$ & $0.80^{*}$ & $0.91^{*}$ \\
Dyspnea scores & $0.37^{*}$ & $-0.45^{*}$ & $-0.45^{*}$ \\
\hline \multicolumn{2}{c}{${ }^{*} \mathrm{p}<0.05}$. & & \\
\hline
\end{tabular}

ening of respiratory function leads to changes in $\mathrm{PaCO}_{2}$ and $\mathrm{PaO}_{2}$ in particular. Compared to $\mathrm{PaCO}_{2}$, a more apparent correlation (table 1) was seen between $\mathrm{PaO}_{2}, \mathrm{SaO}_{2}$ and $\mathrm{SpO}_{2}$ values with an increase in dyspnea scoring. As the dyspnea scoring increased, so did the $\mathrm{PaO}_{2}$ and $\mathrm{SpO}_{2}$ values (table 1).

In determining hypoxemia, compared with ABG values, oxygen saturations obtained with both pulse oximetry $\left(\mathrm{SpO}_{2}\right)$ and $\mathrm{FEV}_{1}$ are highly sensitive, but dyspnea scoring is the parameter that gives the highest sensitivity. Only $\mathrm{SpO}_{2}$ was found to be highly specific in determining hypoxemia (table 2). For the detection of hypercapnia, dyspnea scoring was the most sensitive, whereas the test having the highest specificity was $\mathrm{SpO}_{2}$ (table 3).

The combinations of $\mathrm{FEV}_{1}, \mathrm{SpO}_{2}$ and dyspnea severity scoring resulted in decreased sensitivity $(80.7 \%)$, but increased specificity (88.9\%) for detecting hypoxemia. However, $\mathrm{SpO}_{2}$ alone seemed to be as highly specific as the combination of other tests in the evaluation of hypoxemia. For hypercapnia, the application of these tests together indicated lower sensitivity but higher specificity (73.1 and $78 \%$, respectively) than when used individually.

When the sensitivity and specificity of pulse oximetry analysis were assessed with the ROC curve in the diagnosis of hypoxemia, the area below the curve was determined to be $0.95 \pm 0.02$ (fig. 1). The highest and most acceptable value for sensitivity was $95.6 \%$ and for specificity $80.6 \%$ corresponding to 88.5 , which would be considered the cutoff value of $\mathrm{SpO}_{2}$ (table 4).

\section{Discussion}

For outpatients who are referred to the ED with AECOPD, the morbidity and mortality risk increases if there is a severe functional deterioration. However, sever- 
Table 2. Sensitivity, specificity and predictive values for $\mathrm{FEV}_{1}, \mathrm{SpO}_{2}$ and dyspnea scoring for the detection of hypoxemia using $A B G$ values as the reference

\begin{tabular}{lllll}
\hline \multicolumn{4}{c}{$\mathrm{ABG}$ analysis $\left(\mathrm{PaO}_{2}<60 \mathrm{~mm} \mathrm{Hg}\right)$} & \\
\cline { 2 - 5 } & sensitivity, \% & specificity, \% & PPV, \% & NPV, \% \\
\hline $\mathrm{FEV}_{1}<30 \%$ & $90.3(28 / 31)$ & $26.7(12 / 45)$ & $45.9(28 / 61)$ & $80.0(12 / 15)$ \\
$\mathrm{SpO}_{2}<90 \%$ & $83.9(26 / 31)$ & $88.9(40 / 45)$ & $83.9(26 / 31)$ & $88.9(40 / 45)$ \\
Dyspnea scores $^{1}$ & $93.5(29 / 31)$ & $42.2(19 / 45)$ & $52.7(29 / 55)$ & $90.5(19 / 21)$ \\
\hline
\end{tabular}

$\mathrm{PPV}=$ Positive predictive value $\mathrm{NPV}=$ negative predictive value .

${ }^{1}$ Dyspnea scores of 3 and 4 were regarded as serious dyspnea.
Table 3. Sensitivity, specificity and predictive values for $\mathrm{FEV}_{1}, \mathrm{SpO}_{2}$ and dyspnea scoring for the detection of hypercapnia using ABG values as the reference
Table 4. The various levels of screening cutoff for the detection of hypoxemia by pulse oximetry

\begin{tabular}{lll}
\hline $\begin{array}{l}\mathrm{SpO}_{2} \text { saturation } \\
\text { evaluations, } \%\end{array}$ & $\begin{array}{l}\text { Sensitivity } \\
\%\end{array}$ & $\begin{array}{l}\text { Specificity } \\
\%\end{array}$ \\
\hline 84.5 & 97.8 & 54.8 \\
86.0 & 97.8 & 64.5 \\
87.5 & 97.8 & 74.2 \\
88.5 & 95.6 & 80.6 \\
89.5 & 88.9 & 83.9 \\
90.5 & 71.1 & 96.8 \\
91.5 & 66.7 & 96.8 \\
\hline
\end{tabular}

ity of symptoms and functional parameters may not reflect the real condition of the patient [16-18]. The active use of sternocleidomastoid muscles, pulsus paradoxus, and serious airway obstructions have been detected in only $48 \%$ of the patients that have $\mathrm{FEV}_{1}$ below 1 liter [19]. Poor sensitivity of symptoms alone makes it necessary to assess objective respiratory function of COPD patients in the ED as shown in our study, where $72 \%$ of the patients had clinically serious dyspnea (levels 3 and 4).

Conversely, for the evaluation of respiratory failure in patients with COPD acute attacks, most diagnostic and

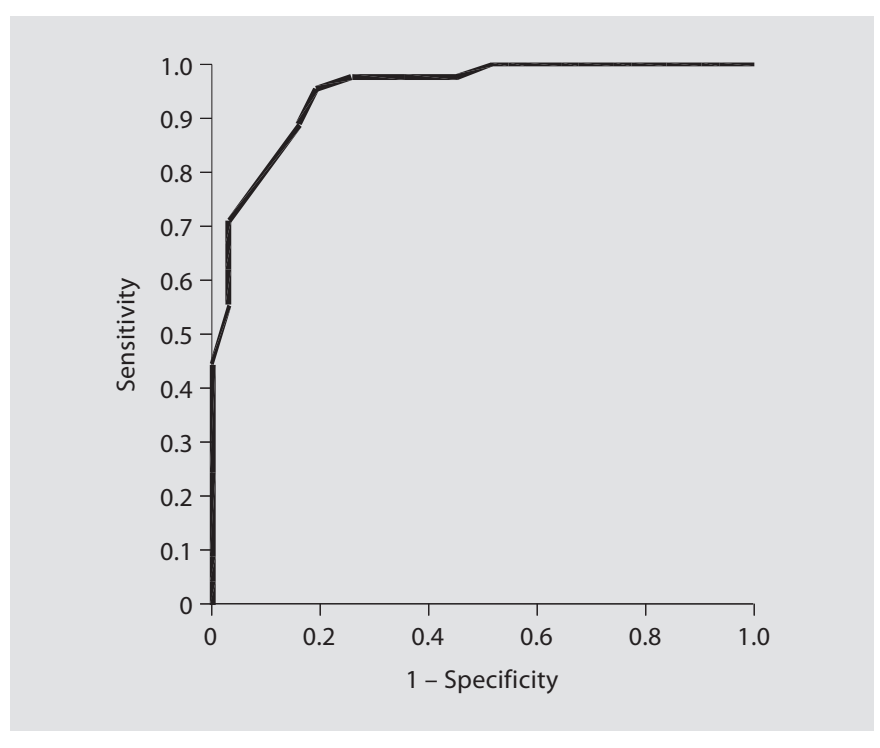

Fig. 1. Demonstration of the sensitivity and specificity of pulse oximetry with the ROC curve in the diagnosis of hypoxemia.

treatment guidelines recommend $\mathrm{ABG}$ analysis. Raffin [20], however, does not recommend this as a specific test for the evaluation of COPD patients. The American Thoracic Society [21] suggests ABG analysis for COPD pa- 
tients whose $\mathrm{FEV}_{1}$ is below 1.5 liters and who have to be hospitalized due to respiratory failure. In our study, when $\mathrm{FEV}_{1}$ was $<30 \%$, the sensitivity was high and the specificity low for the detection of hypoxemia and hypercapnia. Because the specificity of the test was low, only a few of those who were not really sick during the period of acute attack could be identified, thus giving very high false-positive results. Emerman et al. [16] have noted a weak negative correlation between $\mathrm{PaCO}_{2}$ and $\mathrm{FEV}_{1}$ in patients with AECOPD; however, they have not detected such a correlation with $\mathrm{PaO}_{2}$ [6]. We observed a moderate but significant correlation between $\mathrm{FEV}_{1}$ and both $\mathrm{PaO}_{2}$ and $\mathrm{PaCO}_{2}$.

Does $\mathrm{SpO}_{2}$ predict the results of ABG analysis? Currently, in many clinical cases, pulse oximetry is used instead of ABG analysis. For the evaluation of room air ABG results, Witting and Lueck [22] detected the value 96\% for $\mathrm{SpO}_{2}$ when they used the cutoff value for hypoxemia $\left(\mathrm{PaO}_{2}<70 \mathrm{~mm} \mathrm{Hg}\right)$ and hypercapnia $\left(\mathrm{PaCO}_{2}>50\right.$ $\mathrm{mm} \mathrm{Hg}$ ). This level of $\mathrm{SpO}_{2}$ gave $100 \%$ sensitivity and $54 \%$ specificity for hypoxemia. While the sensitivity for hypercapnia remains the same, specificity decreased to $31 \%$ [22]. Also, Neihoff et al. [23] have determined that the value $\leq 94 \%$ of $\mathrm{SpO}_{2}$ detected patients having $\mathrm{PaO}_{2}$ $<70 \mathrm{~mm} \mathrm{Hg}$, with $100 \%$ sensitivity. Considering the cutoff value for $\mathrm{SpO}_{2}$ as $<88.5 \%$, we observed that according to hypoxemia detected by ABG analysis, the sensitivity and specificity of $\mathrm{SpO}_{2}$ was significantly high. Additionally, both the positive predictive value and negative predictive value were also higher for $\mathrm{SpO}_{2}$ than other noninvasive parameters in revealing hypoxemia.

To our knowledge, there is only one study evaluating the role of pulse oximetry in AECOPD [24]. Using a cutoff value of $\mathrm{SpO}_{2} \leq 92 \%$ for those admitted to the $\mathrm{ED}$, these authors reported $100 \%$ sensitivity and $86 \%$ specificity as a screening test for hypoxemia. In the present study, the use of $\leq 88.5 \%$ of $\mathrm{SpO}_{2}$ as the cutoff value gave $96 \%$ sensitivity and $81 \%$ specificity in revealing hypoxemia.

$\mathrm{CO}_{2}$ retention in COPD is a late finding. When the correlation of $\mathrm{PaCO}_{2}$ and $\mathrm{SpO}_{2}$ is evaluated with the patient breathing room air, hypercapnia may be estimated by considering the $\mathrm{SpO}_{2}$ value. Witting and Lueck [22] reported a $\mathrm{SpO}_{2}$ value of $<94 \%$ in patients with a $\mathrm{PaCO}_{2}$ value of $>60 \mathrm{~mm} \mathrm{Hg}$ and $<96 \%$ in those with $\mathrm{PaCO}_{2}$ of $>50 \mathrm{~mm} \mathrm{Hg}$. For $\mathrm{PaCO}_{2}$ values $>50 \mathrm{~mm} \mathrm{Hg}$, the sensitivity and specificity were 100 and $31 \%$, respectively. In our study, the sensitivity of $\mathrm{SpO}_{2}$ in detecting hypercapnia during exacerbation was $73.1 \%$, and the specificity was $76 \%$.
A mild correlation was observed between hypoxemia and hypercapnia with dyspnea scoring. It was also observed that the mean $\mathrm{PaO}_{2}$ value in the cases with dyspnea of 3rd to 4th degree was in accordance with hypoxemia, and hypercapnia was also seen in patients whose dyspnea score was 4 . There was a higher sensitivity but lower specificity than with other tests $\left(\mathrm{FEV}_{1}, \mathrm{SpO}_{2}\right)$ when only dyspnea scores were used in determining hypoxemia and hypercapnia. When dyspnea scoring was added to the other tests, a minimal decrease in the sensitivity of the tests was observed while there was an apparent increase in the specificity. In the hospital EDs where ABG analysis and spirometry are not available, hypoxemic patients can be detected with $81 \%$ sensitivity and $89 \%$ specificity using pulse oximetry and dyspnea scoring. For hypercapnia, the application of these tests together gave lower sensitivity and specificity (73.1 and 78\%, respectively).

One third of the patients required continuous $\mathrm{O}_{2}$, so their $\mathrm{ABG}$ and $\mathrm{SpO}_{2}$ values are likely to meet 'exacerbation' cutoff values all the time. Thirty-one patients (41\%) were determined to be hypoxemic and in the remaining 45 cases, the $\mathrm{PaO}_{2}$ value was $>60 \mathrm{~mm} \mathrm{Hg}$. The average $\mathrm{pH}$ of 7.38 in the hypoxemic group and the lowest $\mathrm{pH}$ of 7.30 suggest that very few were experiencing a significant acute rise in $\mathrm{PaCO}_{2}$ that causes respiratory acidosis. Therefore, it was not possible to evaluate the usefulness of the mentioned noninvasive parameters in acute hypercapnic situations (or respiratory failure), which can be considered an important limitation of the present study.

Nearly $40 \%$ of the patients were hospitalized. The hospitalized patients had lower $\mathrm{FEV}_{1}, \mathrm{SpO}_{2}$ and $\mathrm{PaO}_{2}$ values than nonhospitalized patients. $\mathrm{PaCO}_{2}$ and dyspnea scores were also higher in hospitalized patients. The ongoing symptoms of the patients despite the medical therapy in the $\mathrm{ED}$, and hypoxemia detected in pulse oximetry monitoring guided the decision on hospitalizing patients.

\section{Conclusion}

Although there are objective clinical and noninvasive assessments that reveal the clinical severity during an AECOPD, in this study, the highest sensitivity and specificity was achieved by application of $\mathrm{SpO}_{2}$ alone. This study shows that for patients who are admitted to the ED due to AECOPD, functional deterioration can be easily managed if $\mathrm{SpO}_{2}$ is over $88 \%$; however, if $\mathrm{SpO}_{2}$ is less than $88 \%$, the patients are more likely to receive better care if referred to a clinical center with full monitoring capabilities. 


\section{References}

1 Cydulka RK, Khandelwal S: COPD; in Tintinalli JE, Kelen GD, Stapczynski JS (eds): Emergency Medicine. A Comprehensive Study Guide, ed 5. New York, McGraw-Hill, 1999, pp 485-489.

2 Murray CJL, Lopez AD: Alternative projections of mortality and disability by cause 1990-2020: Global Burden of Disease Study. Lancet 1997;349:1498-1504.

3 Mannino DM: COPD: epidemiology, prevalence, morbidity, and mortality, and disease heterogeneity. Chest 2002;121(suppl 5): 121S-126S

-4 Groenewegen KH, Schols AMWJ, Wouters EFM: Mortality and mortality-related factors after hospitalization for acute exacerbation of COPD. Chest 2003;124:459-467.

5 Emerman CL, Cydulka RK: Use of peak expiratory flow rate in Emergency Department evaluation of acute exacerbation of chronic obstructive pulmonary disease. Ann Emerg Med 1996;27:159-163.

6 Emerman CL, Connols AF, Lukens TW: Relationship between arterial blood gases and spirometry in acute exacerbations of chronic obstructive pulmonary disease. Ann Emerg Med 1989;15:523-527.

7 Emerman CL, Effron D, Lukens TW: Spirometric criteria for hospital admission of patients with acute exacerbation of COPD. Chest 1991;99:595-599.

8 Kesten S, Chapman KR: Physician perceptions and management of COPD. Chest 1993; 104:254-258.
9 Siafakas NM, Vermeire P, Pride NB, et al: Optimal assessment and management of chronic obstructive pulmonary disease (COPD). The European Respiratory Society Task Force. Eur Respir J 1995;8:1398-1420.

10 Global Initiative for Chronic Obstructive Lung Disease: Global strategy for the diagnosis, management, and prevention of COPD. NHLBI/WHO workshop report, publication No 2701. Executive summary, National Institutes of Health, National Heart, Lung, and Blood Institute, 2001.

11 Morgan GE, Mikhail JMS: Patient monitoring; in Clinical Anesthesiology. Los Angeles, Appleton and Lange Limited, 1996.

12 Hanning CD, Williams LM: Pulse oximetry: a practical review. BMJ 1995;311:367-370.

13 Standardized lung function testing. Report working party. Bull Eur Physiopathol Respir 1983;19(suppl 5):1-95.

14 Hamlin MP, Pronovost PJ: Blood gases: pathophysiology and interpretation; in Tintinalli EJ, Kelen GD, Stapczynski SJ (eds): Emergency Medicine, ed 5. New York, McGraw-Hill, 1999, pp 40-150.

15 Fishman A: Approach to the patient with respiratory symptoms; in Fishman A (ed): Fishman's Pulmonary Diseases and Disorders. New York, McGraw-Hill, 1998, pp 362 393.
16 Emerman CL, Lukens TW, Effron D: Physician estimation of $\mathrm{FEV}_{1}$ in acute exacerbation of COPD. Chest 1994;105:1709-1712.

17 Fraser RS, Paré JAP, Fraser RG, Paré PD: Synopsis of the Chest, ed 2. Philadelphia, Saunders, 1994, pp 622-703.

18 Oliver A, Cherniack NS, Deal EC, Kelsen SG: The effects of acute bronchoconstriction on respiratory activity in patients with chronic obstructive pulmonary disease. Am Rev Respir Dis 1985;131:236-241.

19 De Troyer A, Peche R, Yernault JC, Estenne M: Neck muscle activity in patients with severe obstructive pulmonary disease. Am J Respir Crit Care Med 1994;150:41-47.

20 Raffin TA: Indications for arterial blood gas analysis. Ann Intern Med 1986;105:390398.

21 Standards for the diagnosis and care of patients with chronic obstructive pulmonary disease. American Thoracic Society. Am J Respir Crit Care Med 1995;152:S77-S121.

22 Witting MD, Lueck CH: The ability of pulse oximetry to screen for hypoxemia and hypercapnia in patients breathing room air. J Emerg Med 2001;20:341-348.

23 Niehoff J, Del Guercio C, La Morte W, Hughes-Grasberger SL, Heard S, Dennis R, Yeston N: Efficacy of pulse oximetry and capnometry in postoperative ventilatory weaning. Crit Care Med 1988;16:701-705.

24 Kelly AM, McAlpine R, Kyle E: How accurate are pulse oximeters in patients with acute exacerbation of chronic obstructive disease? Respir Med 2001;95:336-340. 